CHARACTERIZATION OF THERMALLY DAMAGED LX-17

P. C. Hsu

July 13, 2007

35th Annual Conference of the North American Thermal Analysis Society

East Lansing, Ml, United States

August 26, 2007 through August 29, 2007 
This document was prepared as an account of work sponsored by an agency of the United States Government. Neither the United States Government nor the University of California nor any of their employees, makes any warranty, express or implied, or assumes any legal liability or responsibility for the accuracy, completeness, or usefulness of any information, apparatus, product, or process disclosed, or represents that its use would not infringe privately owned rights. Reference herein to any specific commercial product, process, or service by trade name, trademark, manufacturer, or otherwise, does not necessarily constitute or imply its endorsement, recommendation, or favoring by the United States Government or the University of California. The views and opinions of authors expressed herein do not necessarily state or reflect those of the United States Government or the University of California, and shall not be used for advertising or product endorsement purposes. 


\title{
Characterization of Thermally-Damaged LX-17
}

Peter Hsu

July 11, 2007

Lawrence Livermore National Laboratory

Livermore, California 94551

\begin{abstract}
Thermal damage was applied to LX-17 at $190{ }^{\circ} \mathrm{C}$ for several hours. The damaged LX-17 samples, after cooled down to room temperature, were characterized for their material properties (density, porosity, permeability, moduli), safety, and performance. Weight losses upon thermal exposure were insignificant (< $0.1 \%$ wt.). The damaged LX-17 samples expanded, resulting in a bulk density reduction of $4.3 \%$.

Subsequent detonation measurements (cylinder tests) were conducted on the thermally-damaged LX-17 samples. The results showed that the fractions of damaged LX-17 reacted were slightly lower than those of pristine LX-17. The thermally damaged LX-17 had a detonation velocity of $7.315 \mathrm{~mm} / \mu \mathrm{s}$, lower than that $(7.638 \mathrm{~mm} / \mu \mathrm{s})$ of pristine LX-17. Detonation energy density for the damaged LX-17 was $5.08 \mathrm{~kJ} / \mathrm{cm}^{3}$, about $9.0 \%$ lower than the detonation energy density of $5.50 \mathrm{~kJ} / \mathrm{cm}^{3}$ for the pristine LX-17. The break-out curves showed reaction zone lengths for pristine LX-17 and damaged LX-17 were similar but the damaged samples had ragged detonation fronts.
\end{abstract}

Keywords: TATB, LX-17, Thermal Damage, Cylinder Test, Detonation Velocity, Detonation Energy, Edge Lag

The $35^{\text {th }}$ Annual Conference of the North American Thermal Analysis Society

August 26-29, 2007

East Lansing, Michigan, USA

* Corresponding author: Peter Hsu, hsu7@1lnl.gov, 925-422-0317

This work was performed under the auspices of the U.S. Department of Energy by the University of California Lawrence Livermore National Laboratory under contract No. W-7405-Eng-48. 


\section{Introduction}

Thermal incidents may expose energetic materials (EM) to unexpected heat that may damage the explosive charge (e.g., change microstructure, introduce voids and porosity, and increase surface area). This may affect material properties, sensitivity, safety, and performance of the energetic materials. Reusing the damaged explosives requires a thorough analysis of the materials. Characterization methods and changes in material properties for thermally damaged HMX-based formulations (LX-04 and LX-10) were reported elsewhere by Hsu et. al [1,2]. LX-04 and LX-10 consist of $15 \%$ and 5\% viton A, respectively and balance of HMX. In general, HMX-based formulations experienced an irreversible volume expansion by more than $5 \%$ after thermal damage at temperature above $170{ }^{\circ} \mathrm{C}$. Both gas permeabilities and burn rates of the damaged samples increased by several orders of magnitude due to higher porosity and lower density. The thermally damaged material also became weaker mechanically and easily to break apart. Some damaged samples were also evaluated at room temperature for their sensitivities to impact, friction and spark (small-scale safety tests). Although no apparent changes in roomtemperature sensitivities were found, the materials may be more sensitive to impact at high temperatures. Urtiew et. al reported that heated LX-04 was more sensitive to shock initiation at high temperatures [3].

Other important factor in considering the reuse of damaged material is its detonation performance (detonation velocity and detonation energy). Hsu et. al [4] recently reported that detonation velocity of thermally damaged LX-04 was 7.7 to $7.8 \mathrm{~mm} / \mu \mathrm{s}$, about $10 \%$ lower than that $(8.5 \mathrm{~mm} / \mu \mathrm{s})$ of pristine highdensity LX-04. Detonation energy density for the damaged LX-04 was $6.5 \mathrm{~kJ} / \mathrm{cm}^{3}$, much lower than the detonation energy density of $8.1 \mathrm{~kJ} / \mathrm{cm}^{3}$ for the pristine high density LX-04. The break-out curves for the detonation fronts showed that the damaged LX-04 had longer edge lags than the pristine high density LX04, indicating that the damaged explosive was less ideal.

LX-17 is a TATB (1,3,5-triamino-2,4,6-tranitrobenzene) -based high explosive developed by Lawrence Livermore National Laboratory (LLNL). It is an insensitive energetic material and is widely used. In this article, we will share our findings on changes in material properties and detonation performance of damaged LX-17.

\section{Characterization of damaged energetic materials}

Explosive charges in either confined (weaponry, munitions) or unconfined (pressed parts, shape charges, or powders stored in warehouses, magazines, bunkers, ships) environments may suffer unexpected insults which may cause undesirable reactions. Examples of insults are fires, earthquakes, problems associated with operational handling, transportation, sudden climate change, and combat operations in battlefields. Safety/sensitivity data for the damaged materials need to be established if the materials are destined for dismantling and demilitarization, as shown in Figure 1. If stakeholders decide to reuse the damaged explosive charges, a comprehensive characterization of the materials would be desirable, as shown in Figure 2. The High Explosives Applications Facility (HEAF) at Lawrence Livermore National Laboratory is a state-of-the-art facility and is dedicated to energetic materials R\&D. It is equipped with many sophisticated devices, equipment, and instruments that offer means for diagnostics and characterization of energetic materials as listed in Table 1. Results of damaged material characterization for LX-04 and LX-10 have been reported elsewhere $[1,2,3,4]$. 


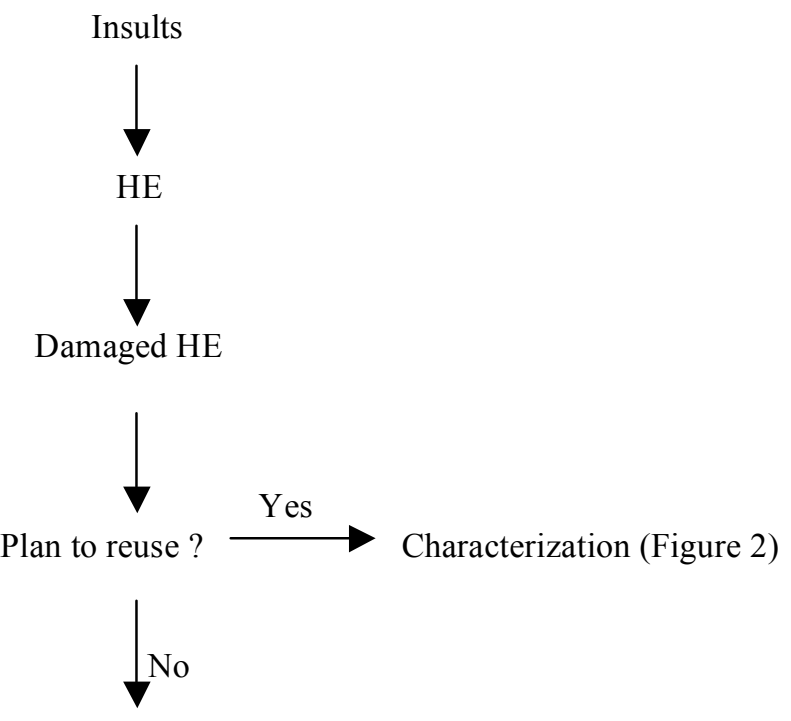

Safety \& sensitivity analysis

(for dismantlement \& demilitarization)

Figure 1. Decision process for the reuse of damaged explosives

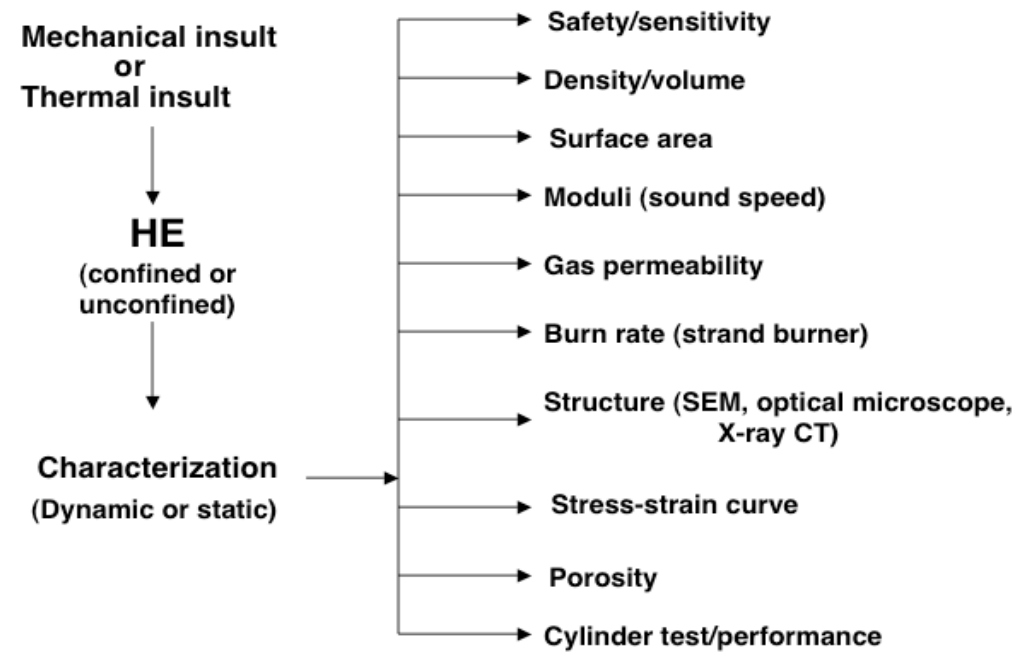

Figure 2. Characterization of damaged energetic materials 
Table 1. System and instruments available for damaged material characterization

\begin{tabular}{|l|l|}
\hline Instruments/equipment & Measurements \\
\hline BET & Surface area \\
\hline Micropycnometer/pycnometer & Volume and density \\
\hline Gas permeameter & Gas permeability \\
\hline Strand burner & Burn rate \\
\hline STEX & Cook off study \\
\hline Ultrasound probe & Sound speed \\
\hline Hopkinson bar & Stress-strain curve at high strain rates \\
\hline Compression equipment, tension equipment & Stress-strain relationship, moduli \\
\hline Drop weight machine & Impact sensitivity \\
\hline Friction test machine & Friction sensitivity \\
\hline Spark test machine & Spark sensitivity \\
\hline Differential scanning calorimetry & DSC \\
\hline Scanning electron microscope & Surface structure \\
\hline Shot tanks up to 10 kg TNT & Shot experiment, cylinder test \\
\hline One dimensional time to explosion system & Thermal kinetics \\
\hline 4” Gun for high-velocity impacting & Run distance to detonation (Pop-plot) \\
\hline
\end{tabular}

\section{Thermal experiments and results}

Thermal damage experiment was conducted remotely in an unconfined environment at high temperature. 12 cylindrical pressed parts of LX-17 (each one was $25.4 \mathrm{~mm} \phi \times 25.4 \mathrm{~mm}$ long) were heated in a $1.0 \mathrm{~kg}$ shot tank at $190{ }^{\circ} \mathrm{C}$ for 4 hours. The samples were then cooled and characterized. Weight losses were only $0.09 \% \mathrm{wt}$, very insignificant. Sample expanded slightly, results in a bulk density reduction of $4.3 \%$, as shown in Table 2 .

Table 2. LX-17 Sample volume and bulk density after thermal damage for each cylindrical part (25.4 $\mathrm{mm} \phi$ $\mathrm{x} 25.4 \mathrm{~mm})$

\begin{tabular}{|c|c|c|c|c|}
\hline Sample & Wt., g & $\begin{array}{l}\text { Bulk volume, } \\
\text { cc }\end{array}$ & $\begin{array}{l}\text { Bulk density, } \\
\text { g/cc }\end{array}$ & $\% \mathrm{TMD} *$ \\
\hline Pristine LX-17 & 24.511 & 12.795 & 1.916 & 98.56 \\
\hline $\begin{array}{l}\text { Heated at } 190 \\
{ }^{\circ} \mathrm{C}, 4 \mathrm{hrs}\end{array}$ & 24.490 & 13.356 & 1.834 & 94.34 \\
\hline$\%$ Change & -0.090 & +4.4 & -4.3 & \\
\hline
\end{tabular}

* TMD (theoretical maximum density) of LX-17 is $1.944 \mathrm{~g} / \mathrm{cc}$ 
Porosity increased after the pressed parts were heated and expanded. Bulk volume of certain sample configurations can be measured accurately by a micrometer and it includes volume occupied by open pores. Blind pores and through pores are open pores which are reachable by gas molecules. The gas pycnometer uses gas displacement principle with a gas pressure of $20 \mathrm{psig}$ and the density obtained from the measurement is called true density. It is very closed to theoretical maximum density (TMD) of the sample if the fraction of closed pores in the sample is insignificant. Total porosity, fraction of closed pores, fraction of open pores can be estimated by Equations 1, 2, and 3. Increase in porosity also resulted in lower mechanical strength (lower moduli), as reported by Hsu et. al. [2].

$$
\begin{aligned}
& \varepsilon=\left(\text { TMD }-\rho_{\mathrm{b}}\right) / \mathrm{TMD} \\
& f_{\mathrm{c}}=\left(\mathrm{TMD}-\rho_{\mathrm{t}}\right) / \mathrm{TMD} \\
& f_{\mathrm{o}}=\varepsilon-f_{\mathrm{c}}
\end{aligned}
$$

Where $\varepsilon=$ total porosity, dimensionless

$\rho_{\mathrm{b}}=$ bulk density, $\mathrm{g} / \mathrm{cc}$

$\rho_{\mathrm{t}}=$ true density, $\mathrm{g} / \mathrm{cc}$

$f_{\mathrm{c}}=$ fraction of closed pores; dimensionless

$f_{\mathrm{o}}=$ fraction of open pores; dimensionless

Table 3 shows the total porosity, fraction of closed pores, fraction of open pores of LX-17 samples after the thermal exposure for 4 hours at $190{ }^{\circ} \mathrm{C}$. The samples became much more porous, evidenced by the increase of total porosity from $2.0 \%$ to $7.4 \%$. Much of the porosity increase came from the open pores (20 times). Similar observation was made on LX-10 [2]. It seems that the use of pycnometer and micrometer can be useful approximation of porosity measurement.

Table 3. Porosity, fraction of closed pores, fraction of open pores of LX-17 samples; samples were cylindrical discs $(25.4 \mathrm{~mm} \phi$ x $5.0 \mathrm{~mm})$

\begin{tabular}{|l|c|c|c|c|c|}
\hline Sample & $\rho_{\mathrm{b}}, \mathrm{g} / \mathrm{cc}$ & $\rho_{\mathrm{t}}, \mathrm{g} / \mathrm{cc}$ & $\varepsilon, \%$ & $f_{\mathrm{c}}, \%$ & $f_{\mathrm{o}}, \%$ \\
\hline Pristine LX-17 & 1.905 & 1.910 & 2.0 & 1.73 & 0.27 \\
& $98.00 \%$ & $98.27 \% \mathrm{TMD}$ & & & \\
& $\mathrm{TMD}$ & & & & \\
\hline Damaged LX-17 & 1.800 & 1.905 & 7.4 & 2.02 & 5.38 \\
& $92.60 \%$ & $97.98 \% \mathrm{TMD}$ & & & \\
& $\mathrm{TMD}$ & & & & 5.11 \\
\hline \% Change & $-5.40 \%$ & $-0.29 \%$ & +5.4 & 0.29 & \\
& & & & & \\
\hline
\end{tabular}

A surface profile meter was used to examine surfaces of damaged parts. The cylindrical parts deformed and concaved, as shown in Figure 3. Up to $0.4 \mathrm{~mm}$ peak was seen on the cylindrical surface. The data were useful for sizing the copper tube for cylinder shots. 

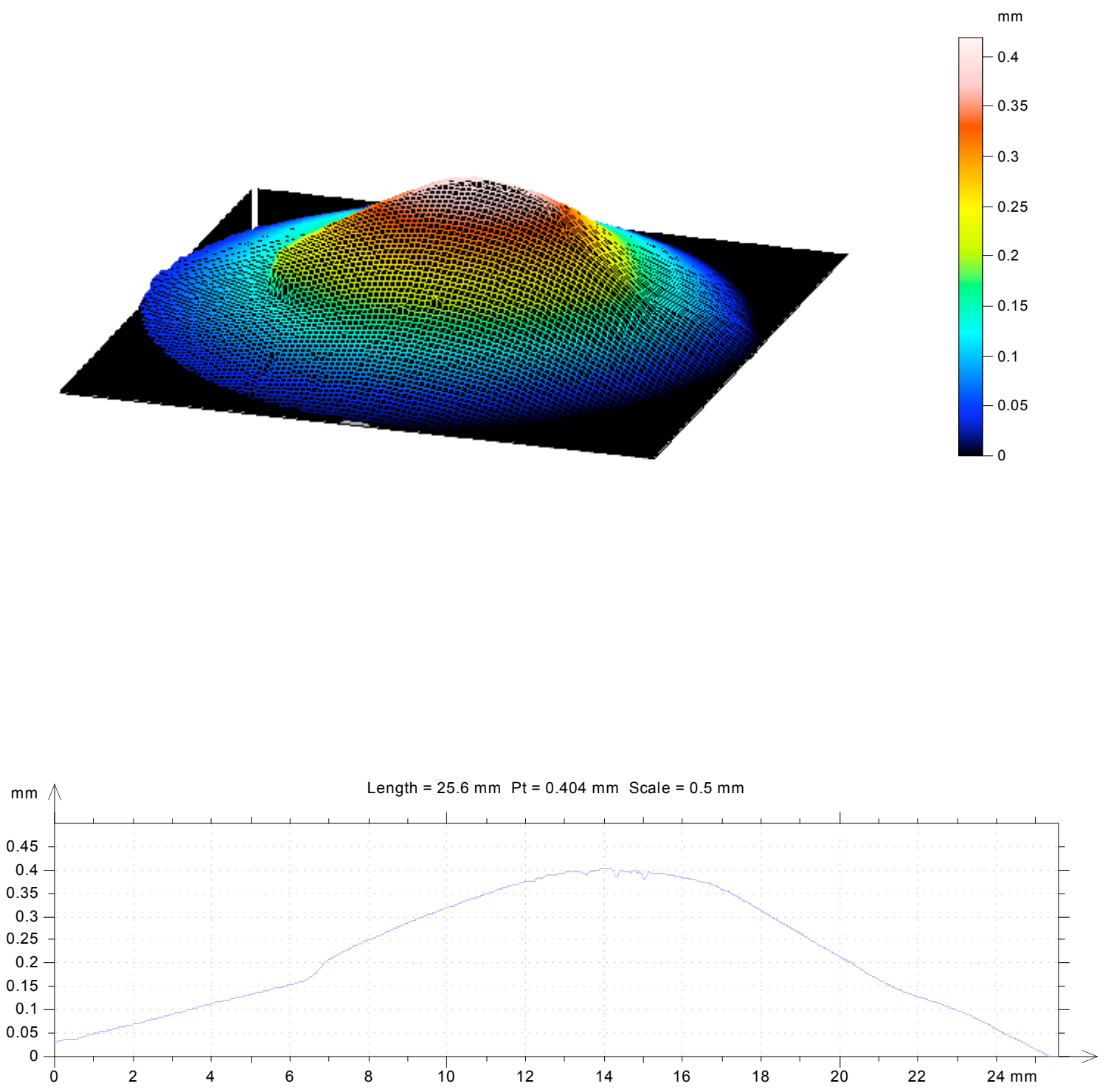

Figure 3: surface profiles of damaged LX-17 samples; profiles shown are for 3D (top) and 2D (bottom)

\section{Detonation experiments and results}

Twelve damaged LX-17 cylindrical samples were assembled inside a copper tube for cylinder test. The cylinder test is a 40 year-old method for measuring the detonation energy at specific relative volumes of expansion, ranging from about 2 to 7 [5]. The detonation velocity is also obtained from the time difference between pin rings and the breakout curvature of the detonation front is taken from a streak camera looking at light from a slit on the detonation front. A typical cylinder test is shown in Figure 3. 


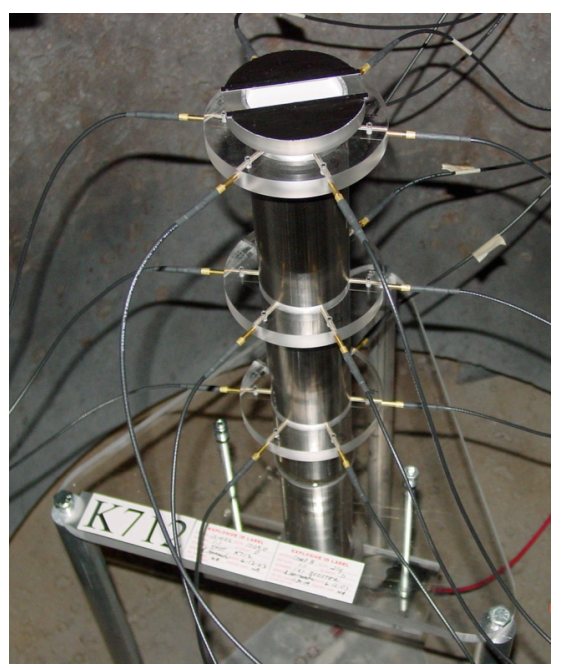

Figure 3. Cylinder test, where the detonation runs upward. The three pins rings are visible as is the end slit for breakout. The laser beam for wall velocity will hit the copper about $2 / 3 \mathrm{rds}$ of the way up. The cylinder sits inside a shrapnel catcher inside the $1.0 \mathrm{~kg}$ shot tank.

Figure 4 shows the measured copper wall velocity for the damaged LX-17 shot (\#769) as lying just below the historical as-pressed results. Four of the old shots were done by streak camera, and the wide scatter is evident. \#628 was done with Fabry interferometry and is directly comparable with \#769. The times are "scaled" to 1-inch diameter, which allows the plotting of various sizes of cylinders with different wall thicknesses. However, \#628 was a 1-inch diameter shot and \#769 is 1.013 inches (because of the swelling), so that the two are directly comparable.

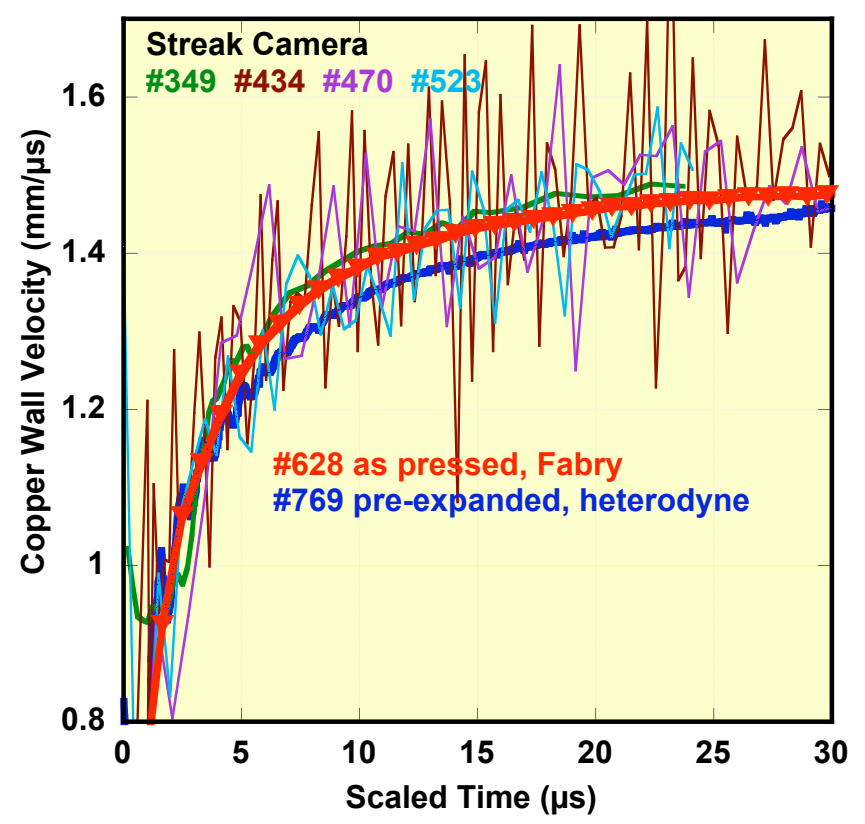

Figure 4. Comparison of copper wall velocities as a function scaled 1-inch diameter times.

The first approach for determining the detonation energy was to equate the square of the copper wall velocity with energies of explosives believed to be near-ideal [6]. Then, the calculated detonation energies 
from the thermo-chemical code CHEETAH became good enough to be used as the standards for full burn [7]. The three standard relative volumes were reset to $2.2,4.4$ and 7.2 for scaled wall displacements of 6 , 12.5 and $19 \mathrm{~mm}$, respectively. For scaling, a $12.7 \mathrm{~mm}$ radius ( 1 inch diameter) tube was taken as the standard. The copper tunes were roughly divided into types: full-wall (radius equal to $1 / 5^{\text {th }}$ radius) and halfwall $\left(1 / 10^{\text {th }}\right.$ radius). Full-wall tubes are the present standard because they are cheaper to make. The halfwall was an attempt to get more velocity in the days of the inaccurate streak camera. At LLNL, the streak camera was replaced by Fabry-Perot interferometry, and that has been replaced in-turn by Ted Strand's Hetereodyne Velocimetry [8]. Both laser methods are more accurate than the streak camera, and the Heterodyne is much cheaper than the Fabry. The error bars for streak camera detonation energies are set at $\pm 3 \%$, although some of this is probably material error. The two laser error bars are lower than $\pm 3 \%$.

The measured wall velocities go into a Gurney-type equation which keeps the density of the copper wall constant with expansion [9]. The equation is

$$
E_{d}=\alpha \beta \rho_{o}\left[\frac{\rho_{m}}{\rho_{o}}\left(\frac{R+x}{R_{o}}\right)^{2} \ln \left(\frac{R+x}{R}\right)+\frac{1}{4}\left(\frac{R+x}{R}\right)^{2}\right] u_{m}^{2}
$$

The result is the detonation energy at some given relative volume, which is described with the measured wall velocity $u_{m}$. $R_{o}$ is the initial radius, $R$ the radius at time $t$ and $x$ the wall thickness at time $t$. The initial densities are $r_{m}$ for the metal and $r_{o}$ for the explosive. $E_{d}$ is the calculated detonation energy and $E_{d}(C h)$ will be the detonation energy from CHEETAH. The coefficients $a$ and $b$ are experimental adjustments for the method of measurement, as described above, and the wall type. This equation allows us to successfully calculate early full-wall shots that used metals other than copper and to adjust for small variations in dimensions. The resulting detonation energy, $\mathrm{E}_{\mathrm{d}}$, is then compared with that calculated by the thermochemical code CHEETAH and the fraction reacted, $\mathrm{F}$, at any relative volume is given by

$$
F=\frac{E_{d}(\text { measured })}{E_{d}(\text { CHEETAH })}
$$

It has become traditional to take special points at scaled wall displacements of $6,12.5$ and $19 \mathrm{~mm}$. The displacement is the measured distance that the outer copper wall has moved, which is directly measured by streak camera and obtained by integration from the laser methods. Scaled means that all cylinders are treated as being $12.7 \mathrm{~mm}$ inner radius ( 1 inch inner diameter). Shot \#757 was 1.05 times larger than 12.7 $\mathrm{mm}$ radius, so that time and displacement (but not velocity) are divided by 1.05 to get the scaled results. Scaling allows comparisons for different geometries. The three displacements mentioned above are correlated to average relative volumes of 2.2, 4.4 and 7.2, respectively. Using the detonation energies at these volumes plus the density and detonation velocity, we can create the JWL Equation-of-State. The Cylinder test and detonation calorimetry are the only methods for obtaining directly-measured detonation energies.

Table 4 shows the results for this shot \#769 plus the historical work done on as-pressed LX-17. The detonation velocity, $\mathrm{U}_{\mathrm{s}}$, is smaller as a result of the lower density. If we use the empirical equation

$$
U_{S}(\text { low }) \approx\left(\frac{\rho_{\mathrm{O}}(\text { low })}{\rho_{\mathrm{O}}(\text { high })}\right)^{2 / 3} \mathrm{U}_{\mathrm{S}}(\text { high })
$$

However, the average fraction reacted is about 0.88 for $\# 769$ and about 0.90 for the as-pressed. We take other empirical equations 


$$
\begin{aligned}
& \mathrm{U}_{\mathrm{S}}(\text { low }) \approx\left(\frac{\mathrm{E}_{\mathrm{d}(2.2 \text { low })}}{\mathrm{E}_{\mathrm{d}}(2.2 \text { high })}\right)^{0.37} \mathrm{U}_{\mathrm{S}}(\text { high }) \\
& U_{\mathrm{S}}(\text { low }) \approx\left(\frac{E_{\mathrm{d}(\text { 4.4low })}}{E_{\mathrm{d}}(\text { 4.4high })}\right)^{0.39} \mathrm{U}_{\mathrm{S}} \text { (high) } \\
& U_{\mathrm{S}}(\text { low }) \approx\left(\frac{E_{d(7.2 \text { low })}}{E_{d}(7.2 \text { high })}\right)^{0.40} U_{S}(\text { high })
\end{aligned}
$$

that relates detonation velocity with the detonation energy density at relative volumes of 2.2, 4.4 and 7.2. The results from these equations are

$$
\begin{aligned}
& \mathrm{U}_{\mathrm{S}}(\text { density }) \approx 7.44 \mathrm{~mm} / \mu \mathrm{s} \\
& \mathrm{U}_{\mathrm{S}}(\text { energy }) \approx 7.40 \mathrm{~mm} / \mu \mathrm{s} \\
& \mathrm{U}_{\mathrm{S}}(\text { measured }) \approx 7.315 \mathrm{~mm} / \mu \mathrm{s}
\end{aligned} .
$$

The first number is on the basis of a density change only and the second on an energy density change only. The actual number is lower, so that it appears from this and the fraction reacted that we have lost some of the actual energy by way of degradation in the process of thermal damage.

Figure 5 shows the detonation front breakout. The front is running downward with the center in front and the edges lagging. The pressed explosive has a nice smooth curve but the expanded sample shows that the holes are making for a ragged front. The edge lags are the same, however, which means that, roughly, the reaction zone lengths are the same. The reaction zone is the distance over which energy comes out of the explosive to push the front ahead. This differed from the LX-04 where the edge lags were about twice as large for the expanded samples. 
Table 4. Detonation velocities and energies for LX-17.

\begin{tabular}{|c|c|c|c|c|c|c|}
\hline $\begin{array}{l}\text { Shot } \\
\text { No. }\end{array}$ & & $\begin{array}{c}\text { Expl. } \\
\text { Density } \\
(\mathrm{g} / \mathrm{cc})\end{array}$ & $\begin{array}{c}\text { Detvel } \\
\# 2 \\
(\mathrm{~mm} / \mu \mathrm{s})\end{array}$ & $\begin{array}{c}\text { Inner } \\
\text { Diameter } \\
(\mathrm{mm})\end{array}$ & $\begin{array}{c}\text { Wall } \\
\text { Thickness } \\
(\mathrm{mm})\end{array}$ & \\
\hline \multirow[t]{2}{*}{769} & Pre-Expand & 1.834 & 7.315 & 25.73 & 2.540 & \\
\hline & average & 1.908 & 7.638 & 25.415 & 3.340 & \\
\hline 349 & full density & 1.900 & 7.630 & 25.414 & 5.210 & \\
\hline 470 & full density & 1.904 & 7.616 & 25.417 & 2.718 & \\
\hline 471 & full density & 1.906 & 7.630 & 25.407 & 2.724 & \\
\hline 522 & full density & 1.908 & 7.640 & 25.414 & 2.723 & \\
\hline 432 & full density & 1.908 & 7.629 & 25.424 & 5.189 & \\
\hline 554 & full density & 1.910 & 7.652 & 25.415 & 2.717 & \\
\hline 439 & full density & 1.912 & 7.650 & 25.412 & 2.714 & \\
\hline 523 & full density & 1.917 & 7.656 & 25.417 & 2.722 & \\
\hline Shot & \multicolumn{3}{|c|}{$\mathrm{Ed}(\mathrm{kJ} / \mathrm{cc})$} & \multicolumn{3}{|c|}{ Fraction Reacted } \\
\hline No. & 2.2 & 4.4 & 7.2 & 2.2 & 4.4 & 7.2 \\
\hline 769 & 4.27 & 4.86 & 5.08 & 0.89 & 0.88 & 0.87 \\
\hline & 4.65 & 5.25 & 5.50 & 0.91 & 0.89 & 0.89 \\
\hline 349 & 4.62 & 5.25 & 5.47 & 0.91 & 0.89 & 0.88 \\
\hline 470 & 4.64 & 5.08 & 5.44 & 0.91 & 0.86 & 0.88 \\
\hline 471 & 4.51 & 5.11 & 5.43 & 0.88 & 0.87 & 0.88 \\
\hline 522 & 4.54 & 5.33 & & 0.89 & 0.90 & \\
\hline 432 & 4.83 & 5.32 & 5.52 & 0.94 & 0.90 & 0.89 \\
\hline 554 & 4.82 & 5.42 & 5.56 & 0.94 & 0.92 & 0.90 \\
\hline 439 & 4.59 & 5.27 & 5.53 & 0.90 & 0.89 & 0.89 \\
\hline 523 & 4.64 & 5.21 & 5.58 & 0.91 & 0.88 & 0.90 \\
\hline
\end{tabular}

\#769 detvel stev $0.007 \mathrm{~mm} / \mu \mathrm{s}$; length $316.7 \mathrm{~mm}$

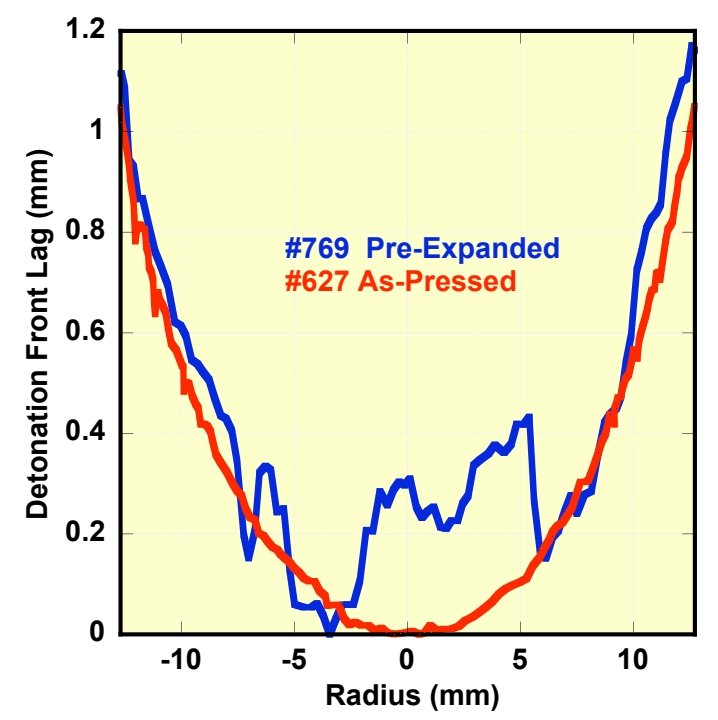

Figure 5. Detonation front breakout curves for LX-17. 


\section{Acknowledgments}

This work was performed under the auspices of the U.S. Department of Energy by the University of California Lawrence Livermore National Laboratory under contract No. W-7405-Eng-48.

\section{References}

1 P. C. Hsu, M. De Haven, M. McClelland, and J. L. Maienschein, Thermal Damage ON LX-04 Mock Material And Gas Permeability Assessment, Propellants, Explosives, Pyrotechnics, 31 (2006) 56.

2 P. C. Hsu, Martin De Haven, Matthew McClelland, Craig Tarver, Steve Chidester and Jon Maienschein, Characterization of Damaged Materials, $13^{\text {th }}$ International Detonation Symposium, Norfolk, Virginia, (2006) to be published.

3 P. A. Urtiew, J. W. Forbes, C. M. Tarver, K. S. Vandersall, F. Garcia, D. W. Greenwood, P. C. Hsu, and J. L. Maienschein, Shock Sensitivity of LX-04 containing Delta Phase HMX at Elevated Temperatures, Shock Compression of Condensed Matter, (2003).

4 P. C. Hsu, P. Clark Souers, Steve Chidester, John Alvarez, Martin De Haven, Raul Garza, Pat Harwood, and Jon Maienschein, Detonation Measurements on Damaged LX-04, Submitted to Propellants, Explosives, Pyrotechnics, March (2007).

5 J. W. Kury, H. C. Hornig, E. L. Lee, J. L. McDonnel, D. L. Ornellas, M. Finger, F. M. Strange and M. L. Wilkens, Metal Acceleration by Chemical Explosives, Proceedings Fourth Symposium (International) on Detonation, White Oak, MD, October 12-15, 1965, Office of Naval ResearchDepartment of the Navy, Washington, D. C., 1965, pp. 3-13.

6 P. C. Souers and J. W. Kury, Comparison of Cylinder Data and Code Calculations for Homogeneous Explosives, Propellants, Explosives, Pyrotechnics, 18 (1993) 175.

7 P. Clark Souers, Jerry W. Forbes, Laurence E. Fried, W. Michael Howard, Steve Anderson, Shawn Dawson, Peter Vitello and Raul Garza, Detonation Energies from the Cylinder Test and CHEETAH V3.0, Propellants, Explosives, Pyrotechnics, 26 (2001) 180.

8 O. T. Strand, D. R.Goosman, C. Martinez and T. L. Whitworth, Compact System for High-Speed Velocimetry using Heterodyne Techniques, Rev. Sci. Instr. 77 (2006) pages not yet listed.

9 John E. Reaugh and P. Clark Souers, A Constant-Density Gurney Approach to the Cylinder Test, Propellants, Explosives, Pyrotechnics, 29 (2004) 124. 